10.1515/ausfm-2015-0011

\title{
Rethinking the Perceived Self: Samples from Facebook
}

\author{
Anita Kasabova \\ NBU, Sofia \\ E-mail: anita.kasabova@gmail.com
}

\begin{abstract}
How the self perceives reality is a traditional topic of research across several disciplines. I examine the perceived self on Facebook, as a casestudy of self-knowledge on "classical" social media. Following Blascovich \& Bailenson (2011), I consider the distinction between the real and the virtual as relative. Perceptual self-knowledge, filtered through social media, requires rethinking the perceived self in terms of social reality (Neisser, 1993). This claim dovetails Jenkins's (2013) notion of the self as an active participant in consumption. I argue that the perceived self in social media could be conceived in terms of how it would like to be perceived and appraised by its virtual audience. Using Neisser's (1993) typology of self-knowledge and Castañeda's (1983) theory of I-guises, I analyse seven samples from Anglo-American and Bulgarian Facebook sites and show that the perceived self produces itself online as a captivating presence with a credible story. My samples are taken from FB community pages with negligible cultural differences across an online teenage/twens (twixter) age group. I then discuss some problematic aspects of the perceived self online, as well as recent critiques of technoconsumerism. ${ }^{1}$
\end{abstract}

Keywords: perceived self, social media, perceived reality, Facebook.

This paper explores the self as it appears to itself and to others online. I argue that perceived reality in social media has as many aspects as there are viewpoints: "what appears to us" is comparable to a patchwork in the making. ${ }^{2}$ (Fig. 1 illustrates perceived reality by means of a token case: "My school," as I see it, as my parents see it, \& as my teachers see it.) I take "social media" to refer to digital communication channels used for engaging in online communication. The perceived self in social

1 This paper was presented at the conference: "Rethinking Intermediality in the Digital Age," organised by the Sapientia Hungarian University at Cluj-Napoca, 24-26 Oct. 2013. I'd like to thank Boyanka Kornazheva and Plamen Velev for their inadvertent feedback, Maria Katsaridou for helpful insights and the participants in the Social Media session for valuable comments and discussion.

2 Thanks to Boyanka Kornazheva for the patchwork metaphor. 
media combines local and global viewpoints, being in "grounded" reality (sitting at the computer) and in virtual reality (online). ${ }^{3}$ My analysis addresses the problem of rethinking the impact of virtual reality on our grounded selves. The perceived self in social media appears in virtual reality and this latter disempowers the traditional notion of reality as the world around and beyond the self.

I focus on the millenial generation's view - a generation also known in the media as the "Me-Me-Me Generation, whose selfishness technology has only exacerbated." "This generation is immersed in virtual reality, yet lives in "grounded" reality. I examine social media mainly used by twixters because that is an age when self-identification is a natural issue. "Millennials are interacting all day but almost entirely through a screen [...]. What they do understand is how to turn themselves into brands, with 'friend' and 'follower' tallies that serve as sales figures," comments Time journalist Joel Stein $(2013,3)$.

The action the perceived self performs on Facebook (from here on abbreviated as FB) is to produce an autobiographical narrative with a likeable protagonist. The narrative's success is measured by the number of "likes" evaluating the perceived self's performance. A well-evaluated self-performance or autobiographical narrative implies that the perceived self is a praised and appreciated self. Online communication allows instant gratification, because technology allows an instant shift from grounded to virtual reality. I argue that the performing self discloses itself online as it would like to be perceived and that this performance has self-efficacy, a notion I explain in section 3. The samples from FB cited in what follows, show how a millenial-generation perceived self produces itself in a social space-time as a captivating presence with a credible story action.

The perceived self on FB is an autobiographical self which constructs an online identity through narrative, yet the perceived self in social media is not limited to pictorial narratives. ${ }^{5}$ Virtual space simulates closeness by bypassing large physical

3 On the use of "grounded" reality, see Blascovich \& Bailenson (2011, 22-24, 29, 54).

4 Cf. Stein (2013,1-2): "Millennials consist, depending on whom you ask, of people born from 1980 to 2000. [...] In the U.S., millennials are the children of baby boomers, who are also known as the Me Generation, who then produced the Me Me Me Generation, whose selfishness technology has only exacerbated.” Cf. also Ben Agger's (2004) definition of the virtual self: "the person connected to the world and to others through electronic means such as the Internet, television, and cell phones. Virtuality is the experience of being online and using computers; it [...] refer[s] to a particular way of experiencing and interacting with the world." I discuss the perceived self in social media, which I take as equivalent to the virtual self in a social structure. Unlike Agger, however, I avoid post-Marxist ideology.

5 Thus algorithm-controlled avatars can take on whatever shapes the grounded self has in mind and act out the latter's desires in online worlds like Second Life. 
distances between participants, so communication takes place in a social space unimpeded by the laws of physics (Blasovich and Bailenson 2011, 135). Roughly put, social media reside in a flat, software-made world, which mirrors our habitually perceived reality. The online autobiographical self occurs and evolves in a social space-time where feedback reflects back on its self-perception and on its evolving self-narrative. Here the protagonist has an unfinished temporal structure, just like its author. This is not the case in traditional autobiography, where the protagonist lacks a temporal horizon, unlike its author. As narratologist Marie-Laure Ryan (2006, 78) puts it: "Life is lived looking forward but it is told looking backward. Whether invented or experienced, events are emplotted retrospectively.” Autobiographical selves in virtual space-time break this rule because they co-exist with their grounded selves in physical space-time. In section 4, below, I give examples of virtual selves whose storyline and timeline diverges from their grounded selves, because virtual selves are uncontrollable and leave non-erasable traces.

The perceived self in social media is a narrator with a point of view, expressed explicitly or implicitly. An autobiographical self is a first-person narrator who is both author and protagonist of her narrative. Points of view belong to a mindset. Philosopher of language Hector-Neri Castañeda (1983) developed this 'mindset' notion with the double connection between singular reference and objects in the world. "Every utterance expressing a thought (whether believed or not) is in principle and at bottom subordinated to an implicit I think that (or, even, to an $I$ say that)" $(1983,60) .{ }^{6}$ Self-perceived reality depends on the viewer's perspective, expressed by the first person (who, namely the self) at a certain time (when), in a certain place (where) and in a certain socio-cultural context (from or in which) it relates to things. These markers coordinate the telling and showing of an event or action by denoting its spatio-temporal position (the content or data to be interpreted) and serve as guidelines for an addressee (“you”) - virtual or grounded. ${ }^{7}$

FB is the context of the self's perceived reality, the content of which is patched together by an online self in relation with itself and other online selves. This self is a multifaceted doublet of " $I$ " and "you," with a double connection between "I" and the objects it refers to (Castañeda 1983, 60-62). In my view, the peculiarity of the perceived self on FB is that it has five roles, meshing grounded and virtual self:

$6 \quad$ The double connection of oratio obliqua and oratio recta, as well as Bühler's work on imagination-oriented deixis and free shiftability is examined by François Recanati (2007), in Perspectival Thought.

$7 \quad$ According to psycholinguists Bühler (1934), Fillmore (1997), Jakobson (1972), Lyons (1975) these are the deictic coordinates of subjective orientation. I examine this in Kasabova (2010). 
(i) The perceived self as it appears to itself (a protagonist in the first person)

(ii) The perceived self as narrator in the first person (an autobiographical self)

(iii) The perceived self in the third-person (an interpersonal self as it appears to others, a participant in a virtual audience)

(iv) The perceived self as protagonist in the second person (a projected self, as it would like to be perceived)

(v) The perceived self as the author (sitting in front of its computer and virtually, as a gossip and trickster)

These five roles map across and correspond to Neisser's (1993) five types of self-knowledge on which my analysis is based. Neisser's (1993) typology of the perceived self divides into 5 types of self-knowledge. (1) the ecological self, which is the embodied self in the physical world and in regard to their immediate environment - the author. (2) the interpersonal self or the relation of the self to other people - the audience. (3) The temporally extended self - the narrator, (4) the private or self-reflective self, and (5) the conceptual or assumptive self.

\section{How the Five Types of Self-Perception Appear in Social Media}

"When you practice for your profile pic" (Fig. 2) is an instance of self-perceived reality online, reframed by Tumblr-hosted community "When you live in Sofia," Sofia's best humor blog. ${ }^{8}$ I argue that perceived reality in social media is not just virtual, but social and interpersonal. I assume that the main roles of the perceived self are intertwined and I reorder them for the purpose of this study: (1) the selfreflective self, namely the self's own perception of itself or, as Neisser calls it, the private self (the protagonist in the first person); (2) the temporally extended self or perceived self-in-process - an autobiographical self with an idealistic narrator; (3) the interpersonal self - engaged in, and receiving feedback from, a social world - and (4) the conceptual or assumptive self which is a projectable and possible self - as it would like to be perceived. From these four types follows (5) Neisser's "ecological" self which inhabits two niches: i) the physical world, as a grounded self in front of a computer and ii) in the virtual world as a gossip and trickster.

The self as it would like to be perceived, (4), is expressed either in the indicative (conditional) or the subjunctive. The self in Fig. 2 expresses what would be the case

8 See: https://www.facebook.com/When YouLiveInSofia. (Last accessed 24. 09. 2014.) This blog shares funny clips which are emblematic of life in Sofia - from falling down a shaft on the street or being overfed by your nan, to despair about the everrising electricity costs and puns about the government. 
if it were perceived as it should be. It is an appellative self-perceived self which wants to appear likeable and to reveal itself to its prospective public as a seductive persona, for the self-perceived self in online networks is an alluring self. Hence I propose the following interpretation of Fig. 2: "If I am seen online, I should look cute, so I have to practice for my profile pic." Namely, the self as it wishes to be perceived - and in order to achieve that effect, the self-reflective self (1) has work to do, to appear as a believable projected self (4). This is the explicit self-reflective self. In addition, the self-reflective self has a sense of humor and pokes fun at itself in indirect speech. The internal structure of the perceived self is expressed in both direct and indirect speech, as a self-reflective and projected/projectable self.

\subsection{The Perceived Self and Its "I-Guises"}

Castañeda (1983) develops the idea that the self has guises - perceived appearances, aspects, and postures and that these guises offer a double connection between singular reference and objects in the world: there is a double relation between word and thought on one hand, and thought and thing, on the other. ${ }^{9}$ The connection between "I" and things is twofold, secured by oratio obliqua and oratio recta, respectively. ${ }^{10}$ While indirect speech implicitly expresses the self's appeal or what it wants to communicate, direct speech explicitly expresses the relation between a grammatical subject and an action in a predicative statement. These statements have an underlying attributive act, such as: "I think here now" or, in our case, "I want here now to be seen as" - which is explicitly expressed by: "you're really awesome."

Consider Fig. 3 "A hard life makes you strong," from Bulgarian twixter communities "Bully, so that they'll respect you" and "I don't care about your opinion." 11 The implicit message is "I want here \& now to be seen as suffering," so that your hard life is appreciated by your peers (the audience). Oratio obliqua shows it is their appreciation or appraisal which makes you strong. The explicit message is that character-building experiences are painful and this is a necessary premiss for making you strong. If you're strong, you'll be respected, is expressed in oratio recta. The perceived reality of the image below shows

9 The issue can be traced back to Aristotle (De Int. I, 16a1-9).

10 This view is shared by Castañeda (1983) and Bühler (1929) and taken up (to some extent) by Recanati (2007).

11 Published on two websites: https://www.FB.com/MackajZaDaTeUvazavat and August 2013 timeline picture of https://www.FB.Com/pages/He-Ме-ИнтересуваМнението-Ви-/305615402903995. Last accessed 24. 09. 2014. 
- both verbally and non-verbally - that respect has to be earned. Hence the message: "you need to prove your worth by beeing seen as having a hard life, on the rocks, at the seaside, your head clasped in your hand." This self-perceived reality is what Castañeda calls a thin slice of a chunk of reality or "I-guise" of a vulnerable but strong twixter. ${ }^{12}$

According to Castañeda, "every statement lies implicitly, or explicitly, in oratio obliqua (indirect speech), and the only true or genuine oratio recta (direct speech) is the unspoken I think [...] or, rather, I think here now. [...] This has momentous consequences for the subject of experience" (1983, 60-61). The subject of experience is the perceived self in its aspects (1) and (4) and the double connection to things is via oratio recta and oratio obliqua. Hence this self is a thin slice of a chunk of reality which Castañeda names I-guise: "A self (conceived as the referent of an indexical use of the first-person pronoun) is not a whole person or total chunk of reality [...]; (2) a self is a thin "slice" of such a chunk; (3) it is a "slice" (hereafter called an I-guise) that consists of being a subject of an experience (whether perceptual or one involving non-perceptual thinking); (4) secondary I-guises are potential subjects of experience; (5) an actual I-guise is a present, presented-to and self-presented subject;" $(1983,61)$.

Castañeda's "I-guises" correspond to Neisser's aspects of the perceived self. An actual I-guise is a present-presented-to and self-presented subject - corresponding to Neisser's (1) the self-reflective or private self which a subject of an experience involving perceptual or non-perceptual thinking which overlaps with (4) the assumptive self which in turn overlaps with Castañeda's (2) secondary I-guise or subject of a potential experience [Fig. 4]. "Only my daughter will be better than me! J" is a good example: the perceived self projects itself into its future, in a bridal outfit, with a daughter dressed as a bridesmaid. The perceived self (secondary I-guise) is a potential bride with a potential daughter. Both of them are studying their reflections in a mirror - needless to add, reflections are also projections, albeit self-presented ones. "Only my daughter will be better than me! J" is an image on the face-book site of Millenials' community "Damn it, I need you!!" 13 Oratio obliqua expresses the subject's wishful thinking here \& now (in a specious present) - how it would like its future or potential self to be, in the I guise of a bride who can be eclipsed only by her future daughter in the you-guise of a potential bride (a bride's maid). Oratio recta expresses the

12 Twixter is a term coined by Time magazine and used by Joel Stein $(2013,3)$ to describe millenials "who prolong a lifestage between teenager and adult."

13 “Мамка му, трябваш ми” at https://www.FB.com/trqbvash.mi. Last accessed 24. 09. 2014. 
actual and self-reflective I-guise in the future tense: "only my daughter will be better than me" - the future tense of the assumed self or secondary I-guise. The actual and secondary I-guises correspond to Neisser's (2) temporally extended autobiographical self. Castañeda says that there is an overlap between the selfreflective self, the specious or temporally extended self, the assumptive or potential self, and the identification of I-guises. "(6) its identification with past or future selves [...]; (7) [...] the time of an experience is a specious present (referred to indexically as now), [...]" $(1983,62)$.

The distinctive feature of an autobiographical self is its temporal extension or continuity spanning from what is to what was and what will be. The time of the autobiographical self is that of a temporally continuous experience in an extended present, referred to indexically as now, as Castañeda points out. This temporally continuous perceived self is extended (or perduring) because it bridges from the present across to the past and future. The autobiographical self perceives reality in a 'specious present' (W. James 1890). The temporally continuous self knows the past mainly on the basis of episodic memory and some semantic memory, as well as the future self of our expectations. Thus the perceived self in the "only my daughter can be better than me" I-guise can project a possible self from its present to its future, by means of epistemic data (knowledge) acquired in its personal past (about brides and bridesmaids, for instance).

The flaw in Castañeda's account is the absence of Neisser's self in relation to other people (3). In my view, the interpersonal self is crucial for relating the various I-guises because it is a source of self-knowledge within the social environment based on perceptual information. Castañeda mentions what could correspond to Neisser's "ecological self," namely "(9) purely physical objects are systems of physical guises;" and we shall test his claim that "one and the same relation glues all guises together, whether physical or mental, or I-guises [...]" (1983, 62). I presume that this I-guises glue is partly composed of the interpersonal self and self-efficacy.

Besides the first-person point of view in social media, an important factor is the third-person perspective, because in social media the self is also perceived from an observer's perspective: she sees herself from her laptop or tablet connected to the web and logged into the social network. This is a tertiary I-guise, corresponding to Neisser's interpersonal self (3). The observer I-guise is not in the scene, although she is experiencing it and self-identifying with it. Hence the interpersonal self overlaps with the other I-guises and contributes perceptual information to self-awareness and self-knowledge of perceived reality, anchoring the other I-guises in a social context. 


\section{How the Interpersonal Self Can Affect the Possible (or Conceptual) Self}

Expounding Neisser's notion, Daniel Stern $(1993,212)$ argues that the interpersonal self has two aspects, subjective and objective, respectively. In a similar vein, I take the conceptual, assumptive or possible self (4) as a doublet, comprising a projectable and a projected self, using the interpersonal self as interface between the possible (its mindset) and the virtually-actual (its online presence). I think the projectable self has a (grammatical) subject: a possible self, actualized in its online projection, whence it provides a feedback which enhances its self-concept. This projected subject provides reassuring feedback to the conceptual or assumptive self via the interpersonal self. Consider the American social network "I know I'm 'awesome,' so I don't care about your 'opinion'." One of the profile pictures shows a hand pointing at the viewer - i.e. the self-perceived self - with the question: "who is the most awesome person today?" [see Fig. 5]. The self-perceived subject receives a reassuring feedback for its possible self: "you are the most awesome person today."

The image can be found on the FB page of a fan community. Thence its interpersonal message spreads its reassurance to self-reflective selves online, allaying their self-doubts and enhancing their self-value in a participatory culture, through spreadable media. For social networking is a cultural practice well supported by fan culture (Jenkins 2013, 9). In addition, social networking is a source of interpersonal knowledge - such as knowing that one is the most awesome person today - which is how that spreadable content affects the perceived self in social media. The perceived storyline on this network acts as a catalyst for a different fan community: the community of the perceived self in various I-guises, from the interpersonal to the possible perceived self. In such a community, says Jenkins (2013, 151-3), consumers are becoming producers because they are engaged in meaningful participation - writing readers, or picture-taking viewers - perceived selves in an interactive reality. An important consequence is that, due to the interpersonal self, the perceived self has acquired new dimensions: it has become a multiversal self in the virtual 2D space of a participatory culture.

In addition, interpersonal self-knowledge is crucial for the perceived self because it is the perceptually based knowledge of a self in interaction with others. Today, face to face interaction with a social partner occurs online and in real time (via Skype). It seems that, for twixters at least, interaction with social partners in social media is a near equivalent to face to face interaction. First, because they usually communicate in a shared social space with members of their ecological 
and social niche. Second, because social partners in social media usually share the same values (since they elected or liked the same network), focus on the same events, objects, or interests, and self-evaluate with regard to their peers on the network. Consequently, the interpersonal self is important for self-recognition, which involves detecting social responses to self-actions.

Via the interpersonal self, the conceptual self receives a relational affect about its perceived status. According to Stern (1993, 206-7), the interpersonal self has a register of so-called categorical affects, such as happiness, sadness, anger, or surprise and these can change over time. Here the temporally extended self comes in, as an autobiographical self with an idealistic narrator connecting the dots of its past and present personae. Part of the interpersonal self's affect-register are relational affects: "feelings of being loved, esteemed, thought wonderful, special or hated, and the feelings of being secure, safe, attached, alone, isolated or separated. These feelings [...] occupy a significant place [...] in research on motivation" (Stern 1993, 207). They are interpersonal feelings arising "in the course of coordinated interactions" and they "push the limits of the interpersonal self, and thus help define its boundaries" (1993, 201).

Consider Fig. 6. "I am simply a person and I make countless mistakes, but you have no right to judge me, because it's my life," from the twixter network "Damn it, I need you." ${ }^{14}$ A black-and-white photograph of a texting girl, presumably texting this missive, either to her bff or her boyfriend.

Interpersonal feelings arise in the course of an interaction coordinated between the interpersonal self, the possible self, the self-reflective self, and the autobiographical self - or the observer, actual and possible I-guises. These three are represented in the image, echoing the interpersonal self's affective mindset feeling misunderstood and depreciated and hence motivated to justify her assumed stance. The actual and possible self are projected in a virtual handshake: the actual private self, in its doublet aspects expressed by the active and passive voice.

The private self has two aspects, active and passive, respectively: an active selfreflective self saying "Iam a person" is judged in a projected passive voice-a judgment the self-reflective self rejects: "you have no right to judge me." The perceived self's motivation lies in the projection of an intimately private self-reflective awareness which is suffering from a harsh judgment. Seen online, the suffering is half as bad, because it is no longer passive but becomes self-effective, due to the observer's I-guise, or the projected interpersonal self which is virtually extended into a social

14 “Мамка му, трябваш ми” at https://www.FB.com/trqbvash.mi (98982 likes on 06. 08. 2013). Last accessed 24. 09. 2014. 
space. The self-reflective and interpersonal self are in their turn interwoven with the temporally extended self which is an autobiographical self.

The autobiographical self is represented as an author/narrator, observed by the interpersonal self, but it too, is a doublet. On one hand, it is framed online as an autobiographical narrator from the observer's third-person I guise. On the other hand, the temporally extended self accounts for the sameness of a sense of self across the time-space between the online projection and the actual projectable self tapping its tablet (or laptop) whilst looking at the screen. This autobiographical self creates its own self (-profile) in a social network, actively participating in consumption (Jenkins 2013, 153).

I suppose the perceived self's online time is analogous to dream-time (except that the perceived self is in waking time), since sequences of events can flash by in a few minutes and, vice versa, what appears as a fleeting glance online may last for an hour. There appears to be a difference in speed between the perceived self's online time and offline time, although, empirically speaking, they should be running at the same speed. The persistence and continuity of that sameness of the perceived self spans across time-space(s) since the perceived self is a self-inprocess. Its extended self-awareness is a necessary condition for putting in order psychical and virtual events. This hybrid self-awareness is warranted by a causal and a semantic link between the self, its actions and its episodes - it's spatiotemporally self-effective parts and its temporal parts.

\section{Self-Efficacy and the Perceived Self's Hero-Paradox}

Self-efficacy is explained by an interaction between the self-reflective self, the autobiographical self, and the interpersonal self. Self-efficacy determines the self's motivational process: for a self to be a motivated self, it needs to notice the relation between its own actions and changes resulting from those actions (EID 2009, 453). The perceived self in social media can construct this causal link by means of its interacting I-guises. The temporally extended autobiographical self does a self-reflective repair-job, intertwined with the interpersonal self. The autobiographical self does this by means of its protagonist in the second person "you" as you would like to be perceived. My claim is corroborated by Josephine Rydberg-Lidén and Mathias Noschis's (2013) research on online audience response and the impact of participatory experience on virtual audience. They found that the impact occurs on an interpersonal level and that the bottom line of individual motivation is that you can affect things - self-efficacy. 
Consider Fig. 7: "I hope you always find a reason to smile" is the message written across a screen showing a lovely, pensive, and unsmiling girl. This image is a profile picture belonging to a Bulgarian twixter network called "Keep quiet and don't get on my nerves" - half-quoting a song by pop-folk singer Galena (2010). ${ }^{15}$ This autobiographical self's narrator is an idealist with an interpersonal counterpart to its self-reflective self - the wounded beauty framed by half-drawn blinds in an umber (or umbrageous) limelight. The projected self is the protagonist in the second person, as it would like to be seen (and comforted). The comforting message: "I hope you always find a reason to smile" is seen by the interpersonal observer-self, from the third-person guise, written by a self-narrator who knows how to heal the "you" protagonist's wounds. The autobiographical consumerauthor participates and consents by "liking" this image.

The paradox underlying the perceived self's efficacy is that the motivated self is an appraised self - even if the appraisal comes from a self-perceived source the likes. Hence the virtual self perceives itself as an agent of a perceived change (a self-efficacious self) in the context of the social media in which it actively participates. Moreover, an appraised self is a hero in the second person. Its performance has to be appraised by the self-reflective self and the interpersonal self, so that its value is secured by a social environment in "the warm embrace of praise," as twixter blogger Stephanie Sparer writes in "Likes' crazy” (2011). The perceived self on FB wants to feel the warm embrace of praise, because it feels like a proverbial underdog and wants to feel like a hero. "I keep forgetting my life is about me. Not what other people think of me," writes Sparer (2011).

The perceived self's hero-paradox, seen in images 3, 6, and 7 also indicates that the perceived self wants to be admired as an underdog. The caption to Fig. 3 showing a girl at the rocky seaside, that reads "A hard life makes you strong!!," asks the underdog to be brave for its audience. Fig. 6 reads "I am simply a person and I make countless mistakes, but you have no right to judge me, because it's my life." It is an underdog pleading for her right to be heard on a website from the viewpoint of a perceived self as an underdog-website called "Bully so that they'll respect you." Fig. 7 appeals "I hope you always find a reason to smile" on behalf of the underdog. The underdog-hero may be a distinctive 21st Century feature of the perceived self in media and literature - an urban nomad, slippery, and mercurial, narcissistic and appealing. Fig. 4, "Only my daughter will be better

15 https://www.FB.com/pages/Тихо-ми-пазии-по-нервите-ми-не-лази/114280678614491 The page was created on $31^{\text {st }}$ January 2013. Galena's song is called “Тихо ми пази и стискай устни” - “Keep quiet and press your lips together.” Last accessed 24. 09. 2014. 
than me!," is emblematic of this stance. The underdog is a young hero - where "young" is a mindset rather than a biological fact - and a negotiator. The self as hero is the "market value" of the main character of the autobiographical self. If the protagonist is appraised as heroic, then it is revealed as an "I don't care about your opinion"-guise because it has received a cognitive and social sanction. ${ }^{16}$ Hence the Bulgarian twixter website has chosen an appropriate name for possible selves that in oratio obliqua would like to be seen as not caring about others' opinion, while the oratio recta expresses their nonchalance.

In a double twist on this moniker, Janky Ror's fanclub page is called "I know I'm 'awesome,' so I don't care about your 'opinion'” The quotation marks around "awesome" and "opinion" signal that this is a received view. An informed interpersonal self knows that it should be called awesome and therefore it does not care about any "opinion" expressed from a second-person-viewpoint, for peer-evaluation is phrased from a third-person-stance. The perceived self's hero paradox: "I don't care about your opinion" explicitly states an underdog's point of view and implicitly sustains an appeal for appraisal and appreciation - so there is no cognitive dissonance between what the perceived self does and believes. Rather, it wants to be acknowledged as a hero in the I-guise of an underdog and combine the self-reflective and autobiographically projected "me" with the interpersonal self in the social context of "what others think about me." Fig . 2, "When you practice for your profile pic," illustrates this point with a sense of humor, another distinctive feature of the millenial generation.

\section{Perceived Self Deviations: "I-Guise" Thieves and Fake FB Profiles}

The downside of the hero-paradox is that the perceived self's desire to be seen and appreciated leaves digital traces which are exploited by others and used for "reality mining" or tracking people's data in order to identify predictable patterns of behavior. Blascovich and Bailenson (2011, 133-135; 154-164) use the term "digital footprints" for the virtual traces our virtual selves leave on the web. Digital footprints provide clues about the self and reveal things about its physical and psychological identity. They are used for database marketing: predicting the self's actions and response, determining the grounded self's identity and personality, collecting, tracking, and brokering their consumer habits. Consequently, in using

16 https://www.FB.com/pages/He-Ме-Интересува-Мнението-Ви-/305615402903995. Last accessed 24. 09. 2014. 
social media we are actively helping corporate interests. In addition, today our personal data are digital collectibles easily mined by third-parties (Marwick 2014).

Digital footprints also foster abuse. Consider Bianca Bosker, a girl whose FB identity was stolen by someone who created a virtual "Bianca Bosker" identity [see Fig. 8]. She writes: "When I finally scoped out this new Bosker [...] I found myself staring back at me" (Bosker 2012). The desire to be seen can rebound unexpectedly: one day you realize that you're being watched and that the information you provided online has been mined and used by others. "Why would someone fake being me - and then friend the real me?" Bosker asks (2012). Performance artist Daiimah Mubashshir has a reply: "FB and Google are not at all interested in recreating identity. I think that these are businesses profiting from data gathering, so the identity piece is just a selling point to keep its users interested." ${ }^{17}$ Mubashshir has two FB profiles (see Fig. 9a): one for her current self, which includes her theater work about being black and lesbian in an Islamic environment, and another for her "old" self, for family and friends, who are not familiar with her work.

Although FB has a real world name policy, many virtual selves on FB are not matched to a grounded user in a way that their author or audience would recognize. Bosker's and Mubashshir's fake profiles both involve name-using practices depending on a producer-consumer relation: Bosker is a consumer who doesn't know the impostor-producer of her fake FB, while Mubashshir is the producer of two FB identities for two different consumer groups which do not recognize her complete identity. Both FB "I-guises" use pseudonyms, but the conditions and motives of this usage are very different (Genette 1987, 50-55). The impostor of the virtual Bianca Bosker profile plagiarizes a grounded identity without the latter's permission and no right of ownership. The producer of two different FB profiles, on the other hand signs them with two names she owns, to avoid being evaluated by the wrong audience. Her reason for having fake FB profiles is that full disclosure isn't an option (Eler 2012).

Consumer-writer Alicia Eler (2012) provides another reason for creating a fake FB profile: "Just for Laughs" [see Figure 9b]. "Baumshaquita (Baum for short) is not a real person. She is a sketch comedy character that I created and sometimes refer to as my 'alter ego."' A real author and grounded self produces an imaginary pseudo-self with some attributes different from the author's: "One time she notso-subtly hit on the person that I was dating. Baum is a general disrupter and Internet loudmouth [...]. She knows a lot of folks that I don't."

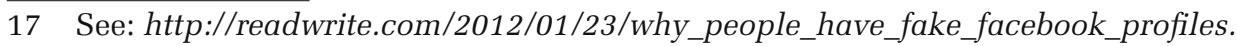
Last accessed 24. 09. 2014. 
A further reason for creating a fake FB profile could be that you're underage: pre-teens are on FB without complying with the terms of service because they like to play games and communicate online. However, the incongruence between grounded self and virtual self may not be due to fake FB profiles. As mentioned above, a virtual self leaves digital footprints. Those traces remain, even if the grounded self tied to them no longer exists: consider FB profiles of deceased users which outlive them as virtual memorials, unless family members have submitted a request to deactivate the account. ${ }^{18}$

\section{Against Technoconsumerism and Social Media}

Last, rethinking the perceived self in social media also involves critiques, such as Dave Eggers's (2013) satire on social media, The Circle. Voted "most admired company four years running," the Circle is a social media corporation combining FB, Google, Twitter, Paypal, Pinternet and others. "There were no more passwords, no multiple identities. Your devices knew what you were and your own identity [...] was the person paying, signing up, responding, viewing and reviewing, seeing and being seen. You had to use your real name, and this was tied to your credit cards, your bank and thus paying for anything was simple. One button for the rest of your life online" (Eggers 2013, 20-21).

The novel mocks the impact of social media on the perceived self, showing how the protagonist, Mae, becomes immersed in the Circle's virtual reality as she battles to increase her participation scores an appraisals. Besides, The Circle is a case of transmedial metalepsis, because it transgresses textual and extratextual boundaries. The author jumps across diegetic (narrative) worlds, combining textual, intratextual, and extratextual levels: first, social media is given a new context in the novel. Second, the author-reader relation spans across the text whose storyline and storyworld parodies social media. The world in which one tells is shifted to the world of which one tells and thus the author manipulates the causal relation between himself, his work, the subject and the audience (Genette 2004, 14; 27; 31).

The movie Disconnect (H. Rubin, 2012) is another case of transmedial metalepsis, expounding the consequences of communication technology and how it affects our relationships. Disconnect is about the dangers of social media and the impact of virtual reality on our daily lives: an ambitious journalist sees a career-making

18 See: http://www.huffingtonpost.com/2012/12/07/death-facebook-dead-profiles_n _2245397.html. Last accessed 24. 09. 2014. 
story in a teen that performs on a chat-room stripper site. A teenager attempts suicide after being bullied by a fake FB identity created by his classmates. After losing their child, a couple stalks the suspect who stole their identity online. Last but not least, my paper could also be seen as a case of transmedial metalepsis: I'm talking about the perceived self in FB-powered reality, jump across to critiques of the perceived self in social media, and cross the textual and intratextual boundaries by communicating it with extratextual readers.

\section{Conclusion}

This paper is an attempt to re-think the perceived self in social media, analyzing the various aspects of that self or I-guise. A spin-off from my analysis reveals what child psychologists call the social contingency detection (EID 2009, 446-449). On this view, infants develop a sense of self only if they can construe a sense of reciprocity with others and a sense of participation in a socio-cultural context. Our perceived self's sense of self depends on its possibility to detect matches between its actions and the wishes and reflections presented by its self-aspects or I-guises. Perhaps the projected self "you, as you would like to be perceived" matches perceptually based knowledge of interacting with others in a narrative by an autobiographical self seeking to appreciate itself in the eyes of others. The perceived self in social media wants to detect a matching of its self-appreciation with social appraisal - in an online mirror, so to speak. This virtual mirror is the perceived self's means to an end, because it affectively biases responses (the likes) while the self notes the effect of its behavior. Detection of social contingency is a work in process and the perceived self is a project to be continued.

\section{References}

Agger, Ben. 2004. The Virtual Self. A Contemporary Sociology. Boston: Blackwell. Benson, J. and B. Heath, eds. 2009. Encyclopedia of Infant and Early Childhood Development. Language, Memory, and Cognition in Infancy and Early Childhood. Oxford: Academic Press, Elsevier (EID).

Blascovich, Jim and Jeremy Bailenson. 2011. Infinite Reality, Avatars, Eternal Life, New Worlds and the Dawn of the Digital Revolution. London: Harper\&Collins. Bosker, Bianca. 2012. I Was Just Befriended by Myself on Facebook. http://www.huffingtonpost.com/2012/11/09/fake-facebook_n_2104102.html. Last accessed 24. 09. 2014. 
Castañeda, Hector-Neri. 1983. The Self and Its Guises. Noûs vol. 17 no. 1: 60-62. Eggers, Dave. 2013. The Circle. London: Penguin.

Eler, Alicia. 2012. Why People Have Fake Facebook Profiles. http://readwrite.com/2012/01/23/why_people_have_fake_facebook_profiles. Last accessed 24. 09. 2014.

Genette, Gérard. 2002 [1987]. Seuils. Paris: Seuil.

Genette, Gérard. 2004. Métalepse: De la figure à la fiction. Paris: Seuil.

Jenkins, Henry, Sam Ford, and Joshua Green. 2013. Spreadable Media. New York: NY University Press.

Kasabova, Anita. 2010. Shifters in Reporting and Recollecting. Analyzing Aspects of Culture. Lexia no. 5-6, CIRCE: 147-177.

Marwick, Alice. 2014. How Your Data Are Being Deeply Mined http://www.nybooks.com/articles/archives/2014/jan/09/how-your-data-arebeing-deeply-mined/. Last accessed 24. 09. 2014.

Neisser, Ulric, ed. 1993. The Perceived Self: Ecological and Interpersonal Sources of Self-Knowledge. New York: Cambridge University Press.

Recanati, François. 2007. Perspectival Thought: A Plea for (Moderate) Relativism. Oxford: Clarendon Press.

Ryan, Marie-Laure. 2006. Avatars of Story. Minneapolis: University of Minnesota Press.

Rydberg-Lidén, Josephine and Mathias Noschis. 2013. The Impact of Participatory Experience on the Audience Stockholm Academy of Dramatic Arts.

Sparer, Stephanie. 2011. "Likes" crazy. http://hellogiggles.com/like-crazy-2. Last accessed 24. 09. 2014.

Stein, Joel. 2013. Millennials: The Me Me Me Generation. http://time.com/247/ millennials-the-me-me-me-generation/. Last accessed 24. 09. 2014.

Stern, Daniel. 1993. The Role of Feelings for an Interpersonal Self, In The perceived self, ed. U. Neisser, 205-215. New York: Cambridge University Press. 


\section{List of Figures}

Figure 1. "My school." An example of perceived reality from Bulgarian teen FB page "long live the uneducated."

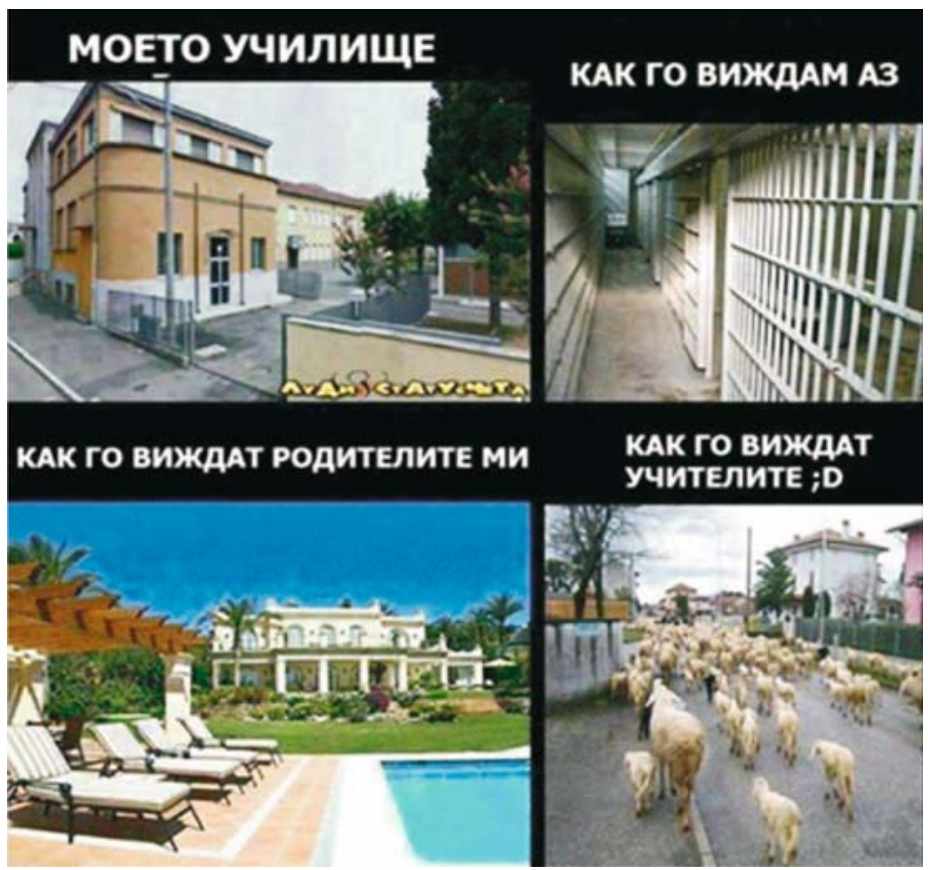

Figure 2. When you practice for your profile pic - a pun on the self-reflective self as it would like to be perceived.

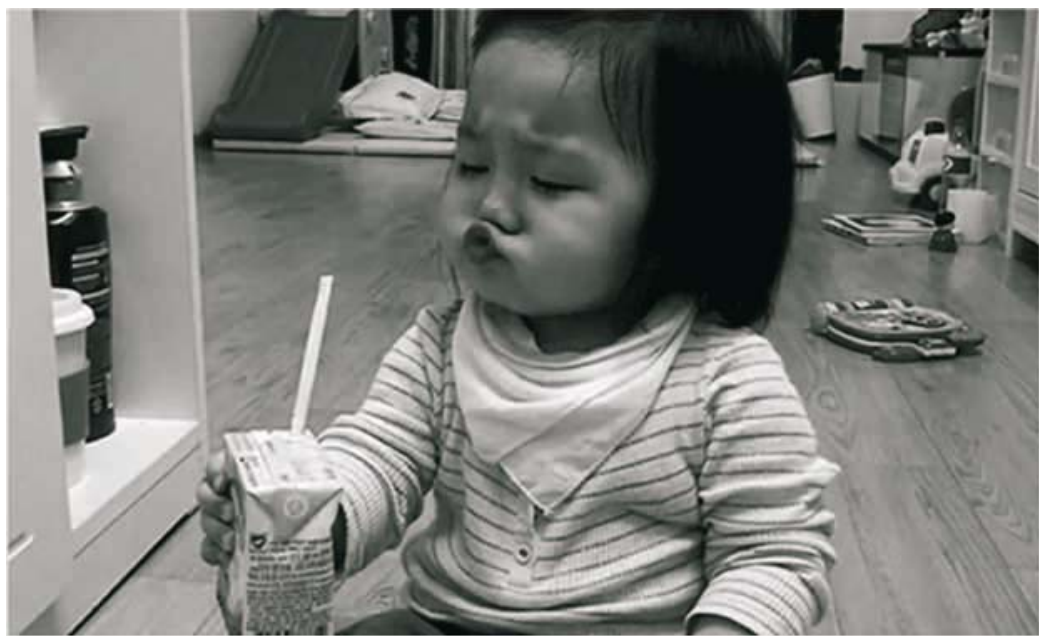


Figure 3. "A hard life makes you strong !!” A twixter 'I-guise.'

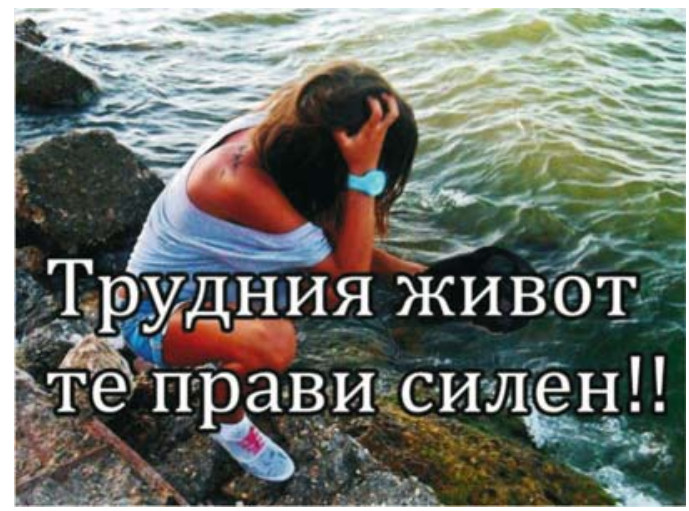

Figure 4. "Only my daughter will be better than me! J"

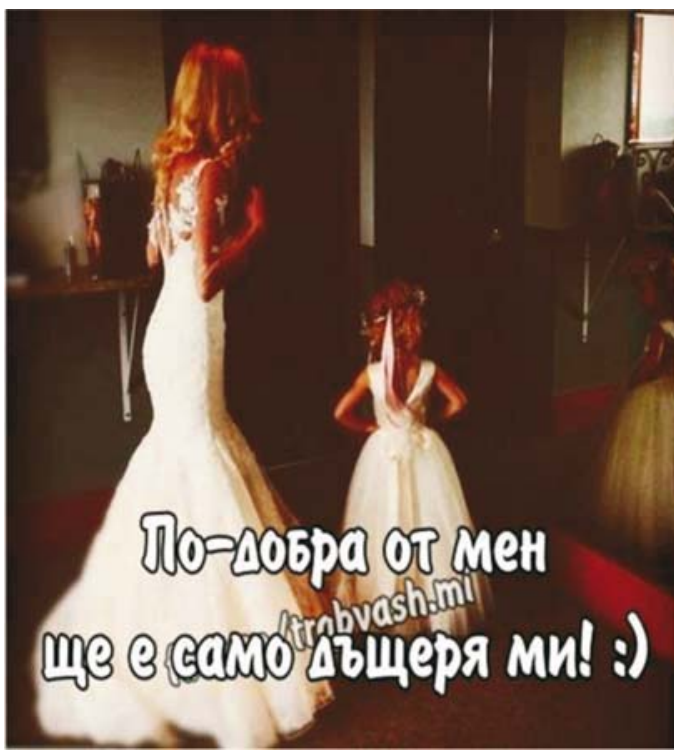


Figure 5. "Who is the most awesome person today?" - how the interpersonal self affects the possible self.

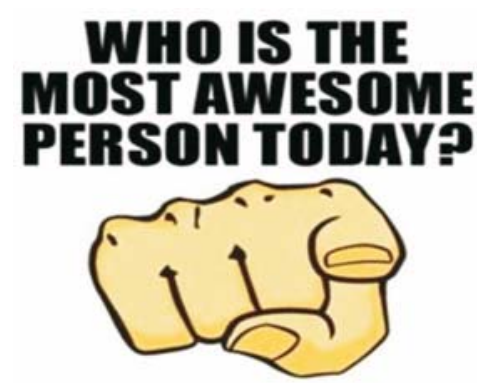

Figure 6. "I am simply a person and I make countless mistakes, but you have no right to judge me, because it's my life."

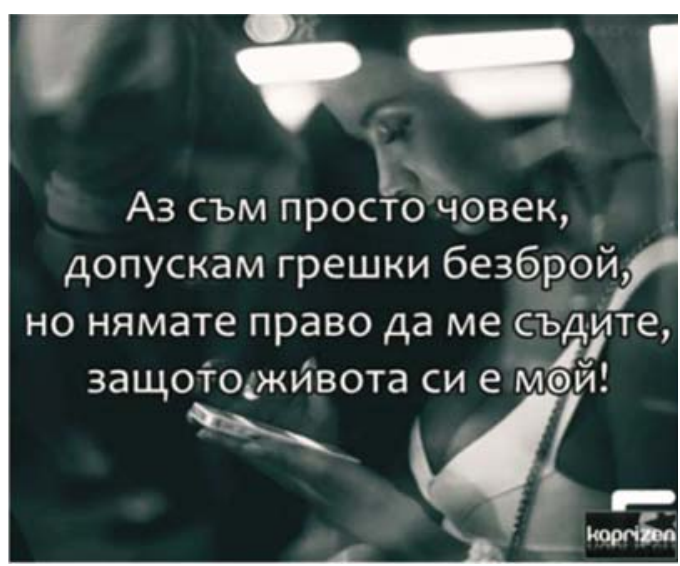

Figure 7. "I hope you always find a reason to smile" - says the autobiographical self's narrator to the self-reflective self and the interpersonal self via the projected self.

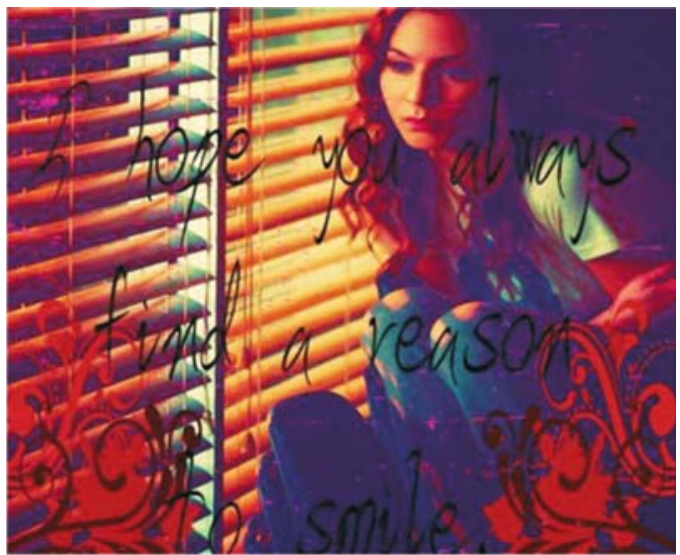


Figure 8. "I-guise" thief (Bianca Bosker, 2012).
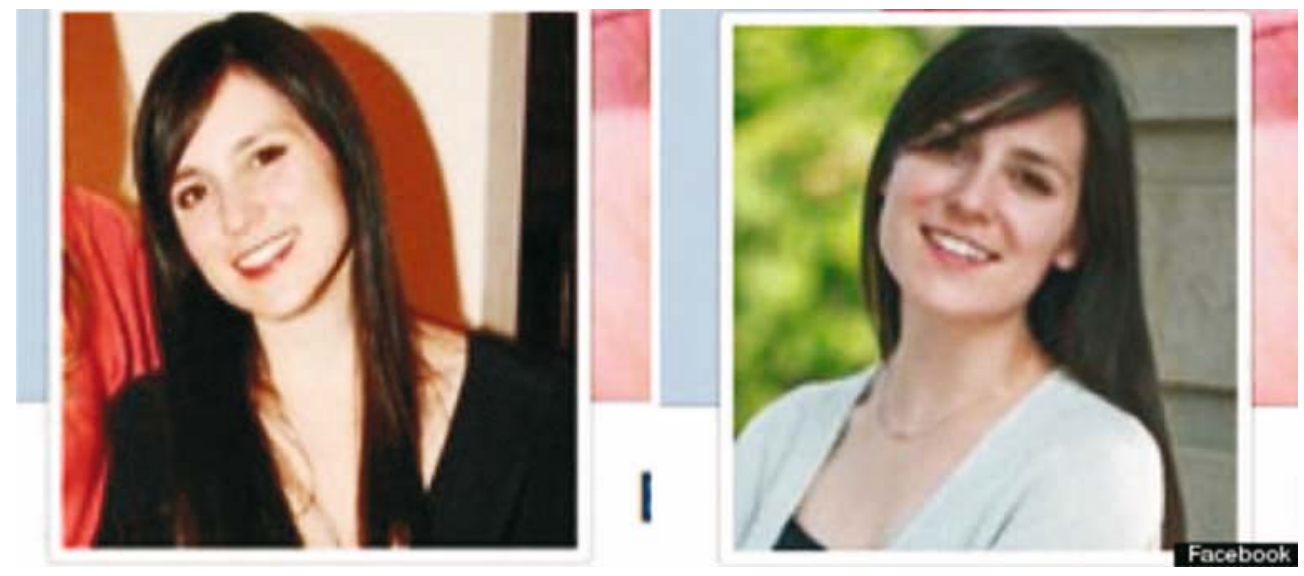

Figure 9. Fake FB profiles: "I-guises" with shifty origins.
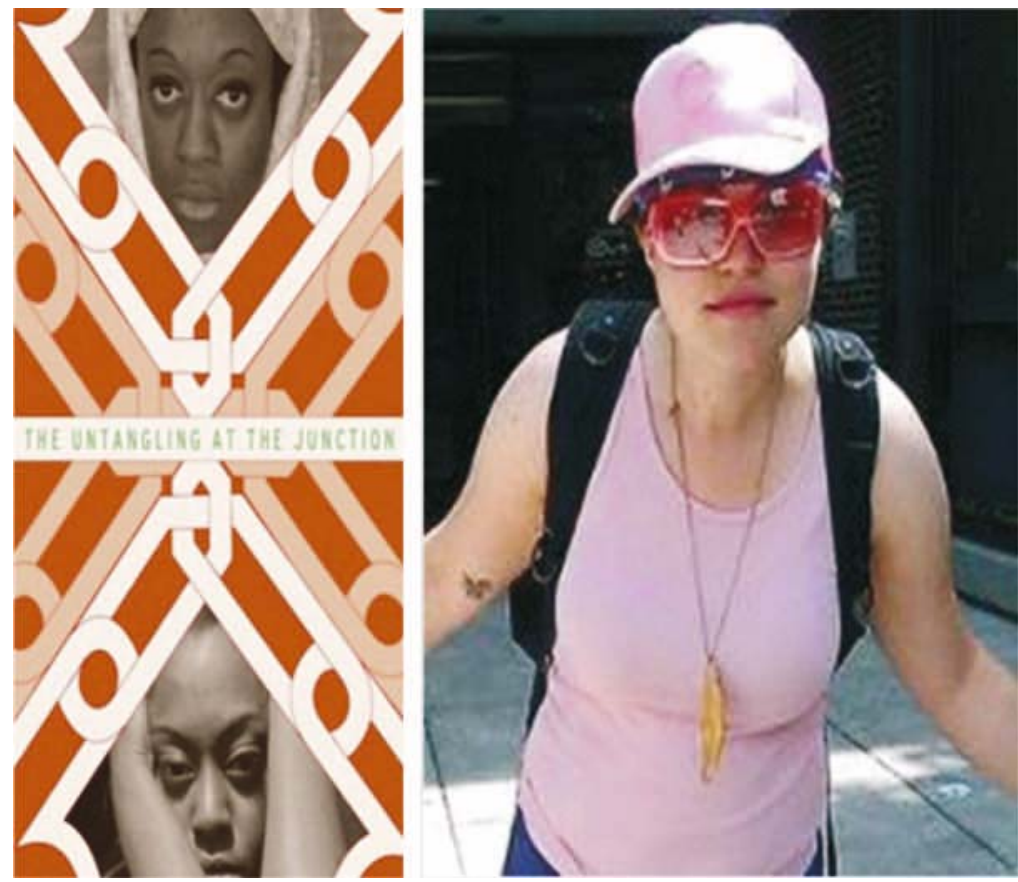